Available online at: http://e-journal.upstegal.ac.id/index.php/jip

Submission: 14-12-2017; Revision: 3-1-2018; Publish Date: 30-4-2018

DOI: $10.24905 /$ jip.v3i1.831

\title{
Meningkatkan Kepercayaan Publik Terhadap Pemerintah Melalui Redesain Proses Kebijakan
}

\section{Lesmana Rian Andhika}

Program Studi Ilmu Administrasi, Fakultas Ilmu Sosial dan Ilmu Politik, Universitas Padjadjaran. Jl. Bukit Dago Utara No. 25 Bandung, 40135, Indonesia.

* Korespondensi Penulis. E-mail: lesmana15001@mail.unpad.ac.id, Telp: +6281617407407

\begin{abstract}
Abstrak
Artikel penelitian ini menawarkan re-desain proses awal kebijakan tingkat lokal. Simulation testing digunakan untuk melihat lebih jauh beberapa konsep yang dapat memengaruhi proses awal kebijakan. Konsep tersebut adalah difusi kebijakan dan dynamic system model, konsep ini digali melalui deduktif untuk mencari beberapa temuan literatur yang relevan dengan tema penelitian. Metode yang digunakan model-building method, sebuah cara untuk merekonstruksi ulang teori dengan cara membangun dari berbagai model. Model yang berasal dari teori, atau menyederhanakan teori yang melibatkan konsep atau hubungan antara konsep internal. Hasil penelitian ini mengungkapkan, meningkatnya atau menurunnya kepercayaan publik juga dipengaruhi oleh kebijakan. Diperlukan cara yang dianggap baru karena probabilitasnya lebih tinggi untuk menghasilkan kebijakan berkualitas dengan mensimulasikan berbagai konsep yang dianggap dapat menerjemahkan berbagai fenomena masalah publik dalam bentuk kebijakan. Disaat ketidakpercayaan publik meningkat, maka itu sebagai respon, dan peringatan kepada pemerintah untuk lebih berupaya meningkatkan kepercayaan publik melalui kebijakan.
\end{abstract}

Kata kunci: Kepercayaan Publik, redesain, Proses Kebijakan

\section{Increase Public Confidence in the Government Through Redesigning the Policy Process}

\section{Abstract}

This research article aims re-design the initial process of local-level policy. Mode simulation testing used to look beyond some concepts that can affect the initial policymaking process. The concept is policy diffusion and dynamic system model this concept was dug through the deductive by searching some of the scientific literature findings to the theme of research. The methods used to a model-building method, a way to reconstruct the theory by means of re-establishing various models. The model is derived from the theory, or simplify the concept or theory that involves the relationship between the concept of an internal concept. The results of this study reveal, the rising or declining public trust is also influenced by the policy. The new way is considered necessary due to the higher probability to produce a quality policy with simulate various concepts that are considered can translate a variety of phenomena in the form of public policy issues. When public distrust is increasing, then that response, and a warning to the government to put more effort into improving public trust through policy.

Keywords: Public Trust, redesign, Policymaking Process 


\section{PENDAHULUAN}

Kepercayaan publik memberikan pengaruh yang besar terhadap berbagai produk yang dihasilkan oleh pemerintah dari produk kebijakan sampai dengan produk pelayanan. Tingkat kepercayaan publik yang tinggi mengindikasikan segala produk yang dihasilkan dapat diterima oleh masyarakat dengan mematuhi segala kebijakan pemerintah. Namun tidak secara otomatis kepercayaan publik akan meningkat dengan sendirinya, tetap ada konsekuensi ketidakpercayaan publik terhadap pemerintah. Hal yang dapat menyebabkan tingkat kepercayaan publik menurun dapat terjadi karena terdapat banyaknya kebijakan pemerintah daerah yang tidak berkualitas. Mengindikasikan menghambat investasi, pembangunan sosial ekonomi, dan kebijakan itu bertentangan dengan peraturan yang lebih tinggi. Kualitas pelayanan birokrasi yang buruk, dan tidak ada keadilan penegakan hukum dari beberapa kasus yang telah diputus oleh pengadilan dan seakan masyarakat percaya bahwa hukum hanya tajam ke bawah tapi tumpul keatas.

Menurunnya kepercayaan publik kepada pemerintah semakin hari semakin meningkat, meskipun bukti empiris terbatas tentang menurunnya kepercayaan publik menjadi pembahasan politik pada era tahun 1960an dan sampai pada era ilmu politik kontemporer, perhatian kepercayaan publik pada pemerintah juga meluas pada kajian administrasi publik dan pelayanan publik (Walle, Roosbroek, \& Bouckaert, 2008; Grimmelikhuijsen \& Knies, 2015). Dari studi organisasi belum diadopsi dalam penelitian tentang ke- percayaan publik terhadap pemerintah dari sudut pandang ilmu administrasi publik dan kebijakan publik (Walle \& Six, 2014). Perdebatan argumentasi konseptual tentang hubungan antara kepercayaan dan kontrol sebagian besar penulis dalam administrasi kebijakan publik memberikan asumsi kehadiran kontrol sama dengan ketidakpercayaan (Rosanvallon, 2008; Frederickson, et al., 2012). Kepercayaan dan ketidakpercayaan memiliki asumsi dari sebuah sudut yang berlawanan, yang datang mungkin saja dalam waktu yang bersamaan. Ada dua hal perbedaan pandangan antara kepercayaan dan ketidakpercayaan dalam administrasi publik dan ilmu politik, pertama perdebatan tentang perlunya kepercayaan dimana beberapa orang berargumen kepercayaan warga itu baik dan tidak percaya itu merusak. Kedua, sementara yang lain berpendapat bahwa ketidakpercayaan warga kepada pemerintah itu rasional dan percaya adalah hal yang naif (Hardin, 2002; Walle \& Six, 2013).

Beberapa argumentasi dapat ditelusuri bahwa kepercayaan publik terhadap pemerintah merupakan cara yang efisien untuk menurunkan biaya transaksi dalam kegiatan sosial, ekonomi dan politik (Fukuyama, 1995). Umumnya kepercayaan akan muncul akibat adanya interaksi interpersonal antara masyarakat dengan pemerintah atau dengan organisasi. Ketika ada kebijakan baru pemerintah yang diumumkan, situasi ini juga menjadi sebab datangnya kepercayaan atau ketidakpercayaan publik terhadap pemerintah. Tidak ada definisi yang mutlak untuk mendefinisikan kepercayaan publik namun, kepercayaan merupakan sebuah 


\section{Jurnal Ilmu Pemerintahan: Kajian Ilmu Pemerintahan dan Politik Daerah, \\ Vol. 3 (1), April 2018 - 26 \\ Lesmana Rian Andhika}

karakteristik, sedangkan yang dirasakan dari kepercayaan itu sendiri menentukan karakteristik yang dirasakan (Chanley, Rudolph, \& Rahn, 2000; Blind, 2006; Grimmelikhuijsen \& Knies, 2015). Secara umum para peneliti mengunakan indikator untuk mengukur tingkat kepercayaan publik sebagai reaksi antara data dan fakta mengapa publik percaya dan tidak percaya terhadap pemerintah. Indikator yang sering digunakan diantanya Eurobarometer, Latinbarometro, BBC, Gallup International Asia Barometer, UNPAN (United Nations in Public Administration and Finance), UNDP (United Nations Development Program), World Economic Forum, World Values Survey, Transparency International.

Beberapa studi telah membuktikan kecenderungan tingkat kepercayan publik meningkat terhadap pemerintah dapat terjadi dari beberapa aktivitas pemerintah seperti tata kelola pemerintah yang baik (Salminen \& IkolaNorrbacka, 2010; Cheung, 2013). Inisiasi Administrative reform (Cierco, 2013; Kim \& Han, 2014), Desentralisasi (Kim, 2010; Tang \& Huhe, 2014), kolaborasi dan partisipasi masyarakat dalam aktivitas pemerintah (Michels \& Graaf, 2010; Tholen, 2015). Namun dibeberapa kondisi dapat meningkatkan ketidakpercayaan publik terhadap pemerintah. Seperti, pelayanan publik buruk diakibatkan oleh patologi birokrasi (Caiden, 1991; Walle \& Bouckaert, 2003; Hacek, Kukovic, \& Brezovsek, 2013). Sistem politik, demokrasi dan penegakan hukum yang buruk (Lindvall, 2011; Trägårdh, 2013; Lenard, 2015). Produk kebijakan yang buruk dapat mempengaruhi kehidupan masyarakat
(Aghion et al., 2010; Bovens \& Hart, 2016).

Memperkuat hasil studi di atas beberapa fakta yang dapat diungkapkan dari laporan Kementrian Dalam Negeri ada sekitar 3.143 peraturan yang dibatalkan, 1.765 Perda/Perkada yang dicabut/direvisi Menteri Dalam Negeri, 111 Peraturan/Putusan Menteri Dalam Negeri dicabut/direvisi Menteri Dalam Negeri, dan 1.267 Perda/Perkada yang dicabut/direvisi oleh Gubernur (Kemendagri, 2016). Ombudsman Republik Indonesia melaporkan, ada 41,59 persen atau 2.853 laporan mengeluhkan pelayanan publik di instansi pemerintah daerah dari total 6.859 laporan secara nasional pada tahun 2015 (Ombudsman, 2016).

Intinya ada banyak konsekuensi yang dapat meningkatkan kepercayaan dan ketidakpercayaan publik terhadap pemerintah. Kepercayaan publik terhadap pemerintah diperlukan oleh rezim penguasa sebagai bahan pertimbangan untuk merumuskan setiap kebijakan. Apakah kebijakan yang langsung bersentuhan dengan masyarakat maupun tidak, dan menjamin kepatuhan masyarakat terhadap kebijakan itu sendiri tanpa paksaan. Ketika masyarakat menarik dukungan kepada pemerintah dan tingkat ketidakpercayaan meningkat maka rezim penguasa dapat untuk dipertanyakan (Blind, 2006; Walle \& Six, 2014). Oleh sebab itu pemerintah memiliki cara tersendiri dari rezim penguasa ke rezim penguasa selanjutnya untuk terus meningkatkan kepercayaan publik. Pasca reformasi Indonesia pada tahun 1998 misalnya, diberlakukan desentralisasi kekuasaan yang sebelumnya sentralisasi, pembentukan Komisi 


\section{Jurnal Ilmu Pemerintahan: Kajian Ilmu Pemerintahan dan Politik Daerah, Vol. 3 (1), April 2018 - 27 \\ Lesmana Rian Andhika}

Pemberantasan Korupsi sebagai respon tinggi nya tindakan korupsi, reformasi birokrasi sebagai upaya perubahan tata laksana kelembagaan dan sumberdaya manusia. Namun sepertinya dari sisi produk kebijakan pemerintah belum menunjukkan hasil yang signifikan untuk meningkatkan kepercayaan publik terhadap pemerintah terutama kebijakan yang dihasilkan oleh Pemerintah Daerah, walaupun dibeberapa daerah menunjukkan tingkat kepercayaan publik meningkat dengan kebijakan rezim penguasa lokal seperti program $e$ government (Kota Surabaya), kebijakan pariwisata (Nusa Tenggara Barat).

Tujuan penelitian ini ingin mengeksplorasi lebih jauh bagaimana meningkatkan kepercayaan publik terhadap pemerintah melalui proses kebijakan dari beberapa temuan konsep literatur yang ada. Walaupun kepercayaan publik lebih banyak dihubungkan dengan proses politik, artikel penelitian ini lebih berfokus kepada mendesain ulang kepercayaan publik melalui proses kebijakan untuk menghasilkan kebijakan tingkat lokal yang berkualitas dari kajian ilmu administrasi publik. Kebijakan yang berkualitas menjadi salah satu cara untuk meningkat-kan kepercayaan publik untuk menyikapi beberapa pertanyaan penelitian, 1). Faktor apa yang dapat menentukan kepercayaan publik terhadap pemerintah; 2). Bagaimana redesain proses kebijakan untuk meningkatkan kepercayaan publik terhadap pemerintah.

\section{METODE}

Artikel penelitian ini diklasifikasikan sebagai studi pendahuluan (preliminary research), bertujuan untuk mereduksi beberapa bukti tertulis yang relevan agar dapat mengungkapkan dan membangun pendekatan yang dianggap bisa menawarkan cara lain tentang tema penelitian. Metode yang digunakan model-building method. Jaccard dan Jacoby (2010) berargumentasi, ... building a theory is choosing a phenomenon to explain or a question/problem to address. Bertujuan untuk merekonstruksi ulang teori dengan cara membangun dari berbagai model. Model yang berasal dari teori, atau menyederhanakan teori yang melibatkan konsep atau hubungan antara konsep dari sebuah konsep internal, terlepas itu simbolis atau representatif. Sebelum membangun kontruksi teori, normanya adalah menggali lebih dalam terhadap berbagai literatur yang relevan.

Penelitian ini dibangun secara deduktif berdasarkan teori ke-percayaan publik dan proses kebijakan untuk mendesain ulang dan menawarkan proses kebijakan dalam mode percobaan atau simulasi dalam menghasilkan kebijakan yang berkualitas untuk meningkatkan kepercayaan publik terhadap pemerintah. Komponen yang disertakan dalam mendesain ulang proses kebijakan tergantung kepada tujuan penelitian, peneliti mengkombinasikan dan dipertimbangkan menggunakan gambar, garis hubungan yang memengaruhi untuk menunjukkan realitas alasan yang dapat disimpulkan. Mungkin saja banyak faktor yang dapat terkait atau sebagian faktor penting yang disertakan. Studi ini akan terus berkembang dari disiplin ilmu yang lain untuk melanjutkan penelitian empiris.

$$
\text { Jaccard dan Jacoby (2010) }
$$

memberikan strategi cara awal yang 
dapat ditempuh untuk membangun ulang teori tersebut adalah, 1). Choosing a phenomenon to explain; 2). Identifying problem areas and questions to focus on is to use the framework of participatory action research; 3). Identify new problems to solve or new questions to answer; 4). Literature reviews. Dalam studi empiris dapat dilanjutkan lebih jauh cara strategi yang dipakai seperti, 1). Heuristic for generating ideas; 2). Idea generation and grounded/emergent theorizing; 3). Twenty-six heuristic; 4). Basic mental or biological processes.

\section{HASIL DAN PEMBAHASAN}

\section{A. Ihktisar Teori Kepercayaan Publik dan Proses Kebijakan Teori Kepercayaan Publik}

Beberapa tahun terakhir istilah percaya dan ketidakpercayaan terhadap pemerintah mamasuki imajinasi populer. Imajinasi yang digambarkan dengan beberapa penolakan terhadap kebijakan pemerintah. Penolakan tersebut dianggap wajar sebagai respon publik terhadap berbagai kebijakan pemerintah. Negara akan menggunakan segala kemampuan dan sumberdaya yang dimiliki untuk memaksa atau tanpa paksaan kepada masyarakat untuk percaya (Chen \& Hua, 2015). Kepercayaan dan ketidakpercayaan adalah hal yang timbal balik seperti dua bilah mata uang yang berlawanan, ketika kepercayaan masyarakat tinggi akan ditunjukkan oleh kemampuan negara dalam mensejahterakan rakyatnya, namun ketika negara tidak mampu untuk mewujudkan kesejahteraan berbagai aksi protes akan mengalir deras dan mengakibatkan masyarakat tidak percaya terhadap rezim penguasa. Lebih jauh, akan mengakibatkan kelumpuhan pe- nyelenggaraan negara, tidak stabilnya sistem politik, krisis ekonomi, krisis kepercayaan yang akan mengakibatkan anarkisme (Reformasi Indonesia tahun 1998, Krisis Yunani tahun 2015).

Ketika terjadi ketidakpercayaan masyarakat terhadap pemerintah, cara yang lebih efisien melalui negosiasi tindakan sosial dan cara komunikasi (Marková \& Gillespie, 2012; Fuoli \& Paradis, 2014). Bentuk negosiasi yang menghasilkan jawaban atas ketidakpercayaan masyarakat terhadap pemerintah, ketika negosiasi berhasil akan mampu memberikan kondisi pemerintahan yang lebih baik dalam menjalankan pembangunan nasional. Namun ketika pemerintah tidak mampu lagi meningkatkan kepercayan publik, konsekuensinya masyarakat akan melakukan berbagai protes. Untuk itu pemerintah akan menggunakan segala sumber daya termasuk berbohong menjadi alat negosiasi yang handal untuk merespon kembali apa yang dilakukan oleh masyarakat (Saz-Carranza \& Serra, 2009; Fähnrich, 2013).

Argumentasi lain juga dapat dijumpai dari Bianco (1994:12) menyebut pentingnya kepercayaan publik, the essence of democracy is that citizens control government by choosing representatives and giving them the power to set public policy using majority rule. Kepercayan publik juga mengambarkan bentuk yang berbeda antara pendelegasian kekuasaan rakyat melalui legislatif dan rasa percaya. Dibanyak argumen akademik mengungkapkan kepercayaan merupakan bentuk ekspektasi atau bentuk perilaku antara seseorang dengan orang lain, seseorang dengan organisasi, seseorang dengan 


\section{Jurnal Ilmu Pemerintahan: Kajian Ilmu Pemerintahan dan Politik Daerah, \\ Vol. 3 (1), April 2018 - 29 \\ Lesmana Rian Andhika}

pemerintah (Hardin, 2002; Kim, 2010; Lindvall, 2011; Walle \& Six, 2014). Walle, Roosbroek, dan Bouckaert, (2008); Walle dan Six (2014) mengidentifikasi kepercayaan dan ketidakpercayaan publik juga dikaji dari beberapa disiplin ilmu pengetahuan seperti psikologi, ekonomi, sosiologi, ilmu politik, studi organisasi, dan administrasi publik. Bagi studi ilmu administrasi publik kepercayaan publik lebih kepada memberikan gambaran tentang usaha pemerintah untuk melakukan perubahan sebagai anti tesis dari berbagai masalah dalam aktivitas pemerintah (lihat lebih lanjut Caiden, 1991). Sepertinya bagi negara berkembang kepercayaan publik dimanifestasikan dengan berbagai aktivitas pemerintah seperti reformasi birokrasi, transparansi, akuntabiltas, partisipasi masyarakat, budaya politik, dan kepercayaan terhadap institusi pemerintah (Kim, 2010; Walle \& Six, 2014).

OECD (2016) memberikan kriteria, 6 areas for government to win back trust, seperti terlihat pada gambar 1 :

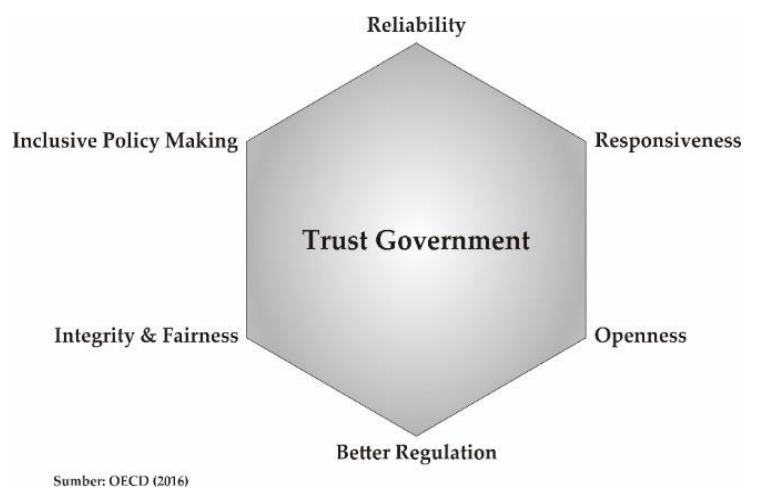

Gambar 1.

Trust Government

a. Reliability;

Pemerintah memiliki kewajiban melindungi warga negara dari ketidakpastian berupa kebijakan dalam lingkungan ekonomi sosial dan politik (OECD, 2016). Sepertinya beberapa negara telah melakukan perlindungan terhadap warga negara dengan berbagai program misalnya pemerintah Indonesia dengan program ekonomi seperti KUR (Kredit Usaha Rakyat), program sosial seperti KKS (Kartu Keluarga Sejahtera), KIS (Kartu Indonesia Sehat), KIP (Kartu Indonesia Pintar). Dibidang politik negara memberikan kebebasan berpendapat dimuka umum, berafiliasi dengan partai politik tertentu, pemilihan umum, pembentukan partai lokal (Kasus Aceh). Pembuatan kebijakan memerlukan pengembangan visi jangka panjang yang mencakup fungsi perencanaan dan peningkatan pemantuan secara berkala termasuk unit evaluasi khusus.

b. Responsiveness;

Kepercayaan pada pemerintah dapat bergantung pada pengalaman warga saat menerima pelayanan publik (OECD, 2016). Buruknya pelayanan publik akan mendorong pemerintah untuk melakukan perubahan mendasar dan komprehensif. Salah satu usaha yang dapat ditempuh dengan gerakan reformasi birokrasi (administrative reform), dengan melakukan perubahan dibidang organisasi, tata laksana, sumber daya manusia, pengawasan, akuntabilitas, pelayan-an publik dan pola pikir, budaya kerja, dan perubahan terhadap peraturan perundang-undangan. Di bawah 
Jurnal Ilmu Pemerintahan: Kajian Ilmu Pemerintahan dan Politik Daerah,

Vol. 3 (1), April 2018 - 30

Lesmana Rian Andhika

kendala fiskal yang ketat dan harapan yang terus meningkat, pemerintah semakin terlibat dengan warga negara untuk memastikan kualitas, daya tanggap dan pada akhirnya mempercayai layanan publik.

c. Openness;

Kebijakan pemerintah terbuka (open government) yang berkonsentrasi pada keterlibatan warga negara dan akses terhadap informasi dapat membantu meningkatkan ke-percayaan publik. Pehaman tentang open government tidak terlepas dari perjalan konsep tata kelola pemerintahan yang baik (good governance). Pemerintah yang membuka diri akan memberikan ruang terwujudnya prinsip-prinsip transparansi, menghilangkan nilainilai komersialisasi pelayanan, dan partisipasi warga negara (Attard, et.al, 2016). Tidak adanya transparansi dalam aktivitas pemerintah akan membuka pintu yang lebar tindakan korupsi (Lindstedt \& Naurin, 2010; Peisakhin, 2012).

\section{d. Better Regulation;}

Membangun, memelihara dan memvalidasi kepercayaan merupakan agenda permanen bagi banyak Negara melalui penerapan praktek peraturan yang baik (OECD, 2016). Kebijakan pemerintah atau kebijakan baru yang akan diumumkan pemerintah dapat meningkatkan dan menurunkan kepercayaan publik terhadap pemerintah. Ketika kebijakan pemerintah tidak menunjukkan berpihak terhadap publik, maka kebijakan itu seperti- nya akan menuai kritik dan bahkan lebih jauh kebijakan itu akan diuji materi kembali, negara memfasilitasi hal itu dengan adanya Makkamah Konstitusi. Bagi pemerintah daerah kebijakan yang buruk diindikasikan bertentangan dengan peraturan yang lebih tinggi, menghambat investasi, menghambat pembangunan sosial, budaya dan ekonomi masyarakat. Sepertinya kebijakan yang buruk cenderung dihasilkan oleh sistem politik yang tidak demokratis dalam analisis kebijakan, sumber daya manusia, dan proses pembelajaran kebijakan yang kurang (AutantBernard, Fadairo, \& Massard, 2013; Bender, Keller, \& Willing, 2014).

\section{e. Integrity \& Fairness;}

Integritas merupakan faktor yang sangat penting dalam menumbuhkan kepercayaan publik (OECD, 2016). Proses politik yang buruk, intervensi politik secara berlebihan dalam birokrasi akan menimbulkan integritas yang rendah (Bozeman, 2000). Ketika birokrasi diintervensi oleh politik secara berlebihan akan mengarah kepada pemusatan kekuasaan. Para elit politik mencoba untuk memengaruhi kegiatan birokrasi untuk kepentingan politik, sisanya para aparatur birokrasi dan sumber daya menjadi eksploitasi permainan para elit politik (Tolbert, 2010).

f. Inclusive Policy Making.

Prioritas bagi pemerintah adalah membangun proses pembuatan kebijakan yang kondusif untuk dipercaya (OECD, 2016). Meningkatkan komitmen untuk melindungi 


\section{Jurnal Ilmu Pemerintahan: Kajian Ilmu Pemerintahan dan Politik Daerah, \\ Vol. 3 (1), April 2018 - 31 \\ Lesmana Rian Andhika}

kepentingan publik dan menjamin proses pembuatan kebijakan yang adil akan meningkatkan keputusan kebijakan, dibangun berdasarkan keputusan yang tepat dengan menggunakan informasi yang andal dan relevan. Anderson (2015) mengidentifikasi proses pembuatan kebijakan yang baik sebagai pola aktivitas sekuensial yang berupa problem identification and agenda setting, formulation, adoption, implementation, evaluation. Pembuatan kebijakan bersifat politis, dalam kerangka yang disederhanakan terbentuknya kebijakan dan diimplementasikan dipandang sebagai hal yang politis karena melibatkan konflik dan perjuangan di antara individu dan kelompok, pejabat dan agensi, dengan gagasan, kepentingan, nilai, dan informasi mengenai isu-isu kebijakan publik.

\section{Teori Proses Kebijakan}

Teknik analisis kebijakan dalam administrasi publik merupakan proses menentukan berbagai kebijakan yang dimulai dari formulasi hingga evaluasi kebijakan dengan serangkaian sasaran berdasarkan hubungan antara kebijakan dan tujuan. Analisis kebijakan lebih populer dilakukan pada sektor publik, namun berlaku juga pada sektor yang lain seperti sektor swasta (organisasi nirlaba, dan organisasi non-pemerintah "NGO"). Pada tahun 1960-an Amerika Serikat melakukan analisis kebijakan yang berakar pada analisis sistem. Kemudian pemikiran analisis kebijakan berkembang dari berbagai ahli dengan sudut pandang yang berbeda. Seperti, Anderson (2015) menyebut proses kebijakan didasari dari problem identification and agenda setting, formulation, adoption, implementation, and evaluation. Walaupun pandangan lain menyebut hal yang hampir serupa dari tulisan klasik seperti Jenkins (1978), Hogwood dan Gunn (1984). Proses kebijakan juga diasumsikan sebagai proses diantara logika dan rasional, prosesnya lebih banyak didasari pada logika politik. Kebijakan akan muncul sebagai respon dari berbagai masalah sosial yang besar (Smith \& Larimer, 2009).

Grindle (1980) memberikan analisis terkait penyelidikannya terhadap proses kebijakan di negara-negara yang ia sebut sebagai dunia ketiga terkait dengan isi kebijakan (content of policy) dan lingkungan implementasi (contex of implementation) yang akan memengaruhi proses kebijakan. Isi kebijakan dalam pandangan Grindle (1980) menyiratkan jenis manfaat kebijakan, perubahan kebijakan, kedudukan pembuat kebijakan, pelaksana program, dan sumberdaya yang dihasilkan dari kebijakan itu sendiri. Lebih lanjut ia mengemukan jenis kebijakan yang dibuat memiliki dampak yang cukup besar terhadap aktivitas politik yang dirangsang oleh proses pembuatan kebijakan. Unsur dari isi kebijakan itu akan mendorong pertimbangan dan kemampuan untuk melakukan implementasi dari berbagai program kebijakan. Sementara itu lingkungan implementasi kebijakan (contex of implementation) menyiratkan adanya aktor yang terlibat (kekuasaan, kepentingan, dan strategi), relasi antara lembaga dan penguasa. Dalam pandangan lain aktor kebijakan dibagi menjadi aktor kebijakan "pemerintah" (instansi 
Jurnal Ilmu Pemerintahan: Kajian Ilmu Pemerintahan dan Politik Daerah,

Vol. 3 (1), April 2018 - 32

Lesmana Rian Andhika

pemerintah "legislatif, eksekutif, yudikatif", kelompok kepentingan), dan aktor kebijakan "non pemerintah" seperti partai politik, warga negara (Rosenbloom, O'Leary, \& Chanin, 2010).

Walaupun pandangan Grindle ini dalam studi implementasi kebijakan diklasifikasikan pada Generasi II (19751980) atau "Building Model clasification" (lihat lebih lanjut O'Toole, 1986; Purwanto \& Sulistyastuti, 2015). Keunikan model Grindle ini berada pada pemahaman yang lebih mendalam terhadap kontek kebijakan yang terkait dengan kebijakan, implementator dan penerima implementasi kebijakan itu sendiri. Bagi negara berkembang seperti Indonesia model ini sering dikaji dan menjadi wacana yang menarik untuk dapat membawa perubahan dalam proses kebijakan. Keadaan yang unik untuk inisiatif kebijakan tertentu memengaruhi dinamika dan proses pengambilan keputusan, walaupun para pengambil keputusan tidak harus menentukan hasil dari proses tersebut. Perubahan dalam proses kebijakan secara umum akan terjadi dan mengikuti reformasi disuatu negara, jenis pejabat publik yang terlibat dalam pengambilan keputusan, tingkat perubahan yang diperkenalkan, dan waktu pengambilan keputusan (Grindle \& Thomas, 1989).

Pandangan post-modern memberikan analisis lebih lanjut proses kebijakan penting untuk mengetahui sejauhmana wacana dan model sistem bergantung kepada model proses kebijakan yang demokratis dimana para politisi mengambil keputusan, aparatur birokrasi senior akan membantu untuk menerjemahkannya dalam berbagai kebijakan pemerintah. Kebijakan mungkin memberikan distorsi terhadap beberapa nilai perspektif empiris, proses kebijakan dalam banyak hal merupakan proses evolusi yang berkesinambungan dimana titik awal yang realistis mungkin jauh tertinggal (Hill, 2005). Nilai dari kebijakan terkait erat dengan nilai-nilai politik, namun secara konseptual berbeda satu dengan yang lain. Nilai politik seperti demokrasi, kesetaraan, dan kebebasan. Nilai kebijakan dimanifestasikan sebagai tindakan nyata dari pemerintah terkadang berjalan lambat dan terkadang berjalan cepat dalam implementasinya (O'Toole, 1986; Stewart, 2009; Gerston, 2010).

\section{B. Faktor Penentu Percaya dan Tidak Percaya}

Berbagai literatur memberikan keterangan, diarea mana kepercayaan dan ketidakpercayaan publik diproduksi. Artikel penelitian ini akan mengeksplorasi area tersebut yang sering dikaitkan dengan produksi kepercayaan dan ketidakpercayaan publik terhadap pemerintah (Bianco, 1994; Blind, 2006; Vincent, 2010; Walle \& Six, 2014; Bovens \& Hart, 2016).

\section{Area Pemerintahan}

Hampir di semua negara liberal dan demokratis menuliskan dalam konstitusinya tentang pengakuan pemerintah daerah (Constitutional and Legal Status), pengaturan pemerintah lokal bukan hanya sebagai pengakuan dari konstitusi namun lebih kepada pengakuan pemerintahan lokal sebagai bagian yang menyeluruh dari sebuah sistem pemerintahan. Konsep dasar desentralisasi bercerita tentang 
Jurnal Ilmu Pemerintahan: Kajian Ilmu Pemerintahan dan Politik Daerah,

Vol. 3 (1), April 2018 - 33

Lesmana Rian Andhika

bagaimana daerah dapat mengelola dan lebih mudah untuk melakukan apapun, namun desentralisasi juga memberikan ruang yang luas untuk melakukan korupsi (Tambulasi \& Kayuni, 2007; Tang \& Huhe, 2014). Inisiasi desentralisasi merupakan bentuk pelimpahan wewenang kepada daerah dan merupakan anti tesis dari sentralisasi. Secara sederhana dipahami bahwa konsep desentralisasi merupakan pilihan politik untuk menyelesaikan masalah-masalah yang terjadi pada daerah, seperti pelayanan publik yang kurang baik. (Shabbir \& Rondinelli, 2007; Holzhacker, Wittek, \& Woltjer, 2016). Dengan adanya desentralisasi tidak ada jaminan masalah dalam aktivitas pemerintah tidak terjadi lagi. Caiden (1991) mengidentifikasi ada sekitar 178 masalah dalam aktivitas pemerintah yang sering disebut sebagai patologi birokrasi yang dapat menurunkan kepercayaan publik terhadap pemerintah. Untuk menyelesaikan berbagai patologi birokrasi itu muncul inisiasi tata kelola pemerintah untuk menjaga kepercayaan publik seperti good governance, sound governance, dynamic governance, open government, sampai dengan inisiasi reformasi birokrasi (administrative reform) yang dituangkan dalam berbagai bentuk kebijakan pelayanan publik. Pelayanan publik yang baik dapat meningkatkan kepercayaan publik terhadap pemerintah (Walle \& Bouckaert, 2003; Salminen \& Ikola-Norrbacka, 2010; Tang \& Huhe, 2014).
2. Area Sistem Politik

Ungkapan eufemisme menjadi seolah-olah berbentuk klise seperti perang adalah damai, kebebasan adalah perbudakan dan ketidaktahuan adalah kekuatan pada akhirnya akan memicu kegaduhan stabilitas politik antara beberapa kelompok elit penguasa. Sistem politik yang baik dalam keadaan normal akan meningkatkan investasi dan pertumbuhan ekonomi. Sistem politik yang baik juga akan memengaruhi setiap kebijakan yang dihasilkan. Setiap negara memiliki philosophy berbeda dengan sistem politik yang mereka anut. Secara ontologi penerapan sistem politik yang dianut tidak terlepas dari sejarah sebuah negara. Beberapa idiologi politik yang mengajarkan beberapa hal yang berbeda seperti misalnya sistem politik liberalism, conservatism, socialism, anarchism, fascism, feminism, ecologism, nationalism, fundamentalism, icon and iconoclasm (Vincent, 2010). Kepercayaan publik akan meningkat ketika sistem politik yang baik menjadi cerminan kehidupan berbangsa yang dapat mengatur secara adil, dan demokrasi yang baik (Aghion, et.al, 2010; Lenard, 2015; Bovens \& Hart, 2016).

Konsekuensi dari area produksi kepercayaan dan ketidakpercayaan publik di atas akan memberikan efek terhadap dua aspek yaitu pemerintah dan masyarakat melalui berbagai produk kebijakan. Kebijakan yang berkualitas dapat meningkatkan kepercayaan publik terhadap pemerintah, (Kim, 2010; Wilkes, 
2015; Oomselsat et al., 2016). Kedua aspek tersebut seperti dua arah yang saling membutuhkan seperti terdeskripsi pada Tabel 1:

Yang patut diwaspadai ketika publik tidak percaya kepada pemerintah, kondisi ini akan dimanfaatkan oleh sekelompok orang untuk kepentingan pribadi dan kelompok (Fuoli \& Paradis, 2014). Sebagai contoh, buruknya tata kelola pemerintah akan berdampak pada terhambatnya pembangunan suatu negara, membuka pintu korupsi, pelayanan publik yang buruk. Kondisi seperti ini akan menarik negara maju (negara donor) dengan alasan ingin membantu, namun perlu diperhatikan teori defedensi mengajarkan kita akan ketergantungan kepada negara-negara maju seolah menjadi rujukan utama setiap langkah kebijakan yang mereka putuskan dan harus dilaksanakan menjadi obyek trial and error policy. Tidak ada cara lain, mengikuti sebagai obyek pemasaran produk (kebijakan, perdagangan) negara donor dan negara penerima donor akan lebih kepada negara konsumtif. Kita masih ingat konsep Governance and Development, berawal dari kasus sub-sahara Afrika pada tahun 1990-an, bahwa pemerintah adalah sumber kegagalan pembangunan. Oleh sebab itu Good governance adalah alat lembaga neoliberal (lembaga donor) untuk melancarkan pembangunan kapitalisme dunia (Rindermann, KodilaTedika, \& Christainsen, 2015).

\section{Redesain Proses Kebijakan}

Proses kebijakan yang baik salah satu cara untuk meningkatkan kepercayaan publik dengan memroduksi kebijakan tingkat lokal yang berkualitas, walaupun masih banyak cara dalam aktivitas pemerintah untuk meningkatkan kepercayaan publik yang pernah diungkapkan dari beberapa literatur seperti, reformasi birokrasi, inisiasi inovasi dalam aktivitas pemerintah, tata kelola pemerintah, anti korupsi, dan lain sebagainya. Redesain proses awal kebijakan ini akan mencoba memberikan pemikiran yang konstruktif untuk menyikapi fenomena masalah yang terdeskripsi dalam latar belakang penelitian. Banyaknya kebijakan tingkat lokal yang bermasalah menjadi indikasi adanya permasalahan yang serius untuk memroduksi kebijakan tingkat lokal yang tidak bertentangan dengan aturan yang lebih tinggi. Oleh sebab itu, peneliti mencoba mendesain ulang produksi kebijakan tersebut dari komparasi konseptual teoritis yang relevan, dan juga mencoba memberikan kontribusi pengetahuan.

Walaupun sepertinya berbagai argumentasi konsep atau teori menyebut proses kebijakan tidak memiliki keseragama definisi, namun secara umum artikel penelitian ini menggunakan pendekatan proses kebijakan dapat diidentifikasi dari problem identification and agenda setting, formulation, adoption, implementation, and evaluation (Anderson, 2015). Namun aktivitas yang normal ini sering tidak didukung oleh produksi kebijakan dengan kualitas yang baik. Untuk memulai pemikiran re-desain kepercayaan publik melalui proses kebijakan yang berkualitas dapat dilihat pada Gambar 2:

Banyak cara yang dapat dilakukan untuk memproduksi kebijakan yang berkualitas, ukuran kualitas kebijakan me 


\section{Jurnal Ilmu Pemerintahan: Kajian Ilmu Pemerintahan dan Politik Daerah, Vol. 3 (1), April 2018 - 25 \\ Lesmana Rian Andhika \\ Tabel 1. \\ Efek Percaya dan Tidak Percaya}

\begin{tabular}{|c|c|}
\hline Pemerintah & Masyarakat \\
\hline \multicolumn{2}{|c|}{ Percaya (Trust) } \\
\hline $\begin{array}{l}\text { - Pemerintah lebih mudah untuk } \\
\text { menjalankan fungsinya, kepercayaan } \\
\text { kepada institusi pemerintah akan sangat } \\
\text { mudah menyukseskan kebijakan } \\
\text { pemerintah; } \\
\text { - Memberikan peluang investasi dari pihak } \\
\text { asing, meningkatkan kepercayaan diri dari } \\
\text { investor dan konsumen; } \\
\text { - Pemerintah lebih mudah untuk } \\
\text { menjalankan pembagunan nasional melalui } \\
\text { program-program dan peraturan; } \\
\text { - Kesuksesan kebijakan publik yang luas } \\
\text { tergantung pada pola perilaku publik; } \\
\text { - Kepercayaan menjadi kunci aktivitas } \\
\text { ekonomi dan keuangan. }\end{array}$ & $\begin{array}{l}\text { - } \text { Tingkat kebahagian hidup semakin tinggi } \\
\text { pada suatu negara; } \\
\text { - Angka kemiskinan akan semakin } \\
\text { berkurang; } \\
\text { - Masyarakat lebih bermakna dimata } \\
\text { pemerintah karena ikut berpartisipasi } \\
\text { dalam pembangunan nasional; } \\
\text { - Keterbukaan pemerintah akan } \\
\text { memudahkan masyarakat untuk } \\
\text { mengakses segala informasi tentang } \\
\text { program, regulasi, kebijakan pemerintah. }\end{array}$ \\
\hline
\end{tabular}

\section{Tidak Percaya (Distrust)}

- Investasi asing akan menurun sehubungan dengan maraknya kasus korupsi, tidak adanya kepastian hukum, prosedur yang panjang dan berbelit yang akan memengaruhi pertumbuhan ekonomi;

- Stabilitas keamanan terganggu dengan isu terorisme, radikalisme.

- Akan meningkatkan angka kemiskinan karena pertumbuhan ekonomi terhambat;

- Kualitas pelayanan publik yang buruk akan mengalihkan masyarakat untuk menggunakan pelayanan publik yang disediakan oleh swasta.

\section{Sumber: diolah dari data sekunder (2017)}

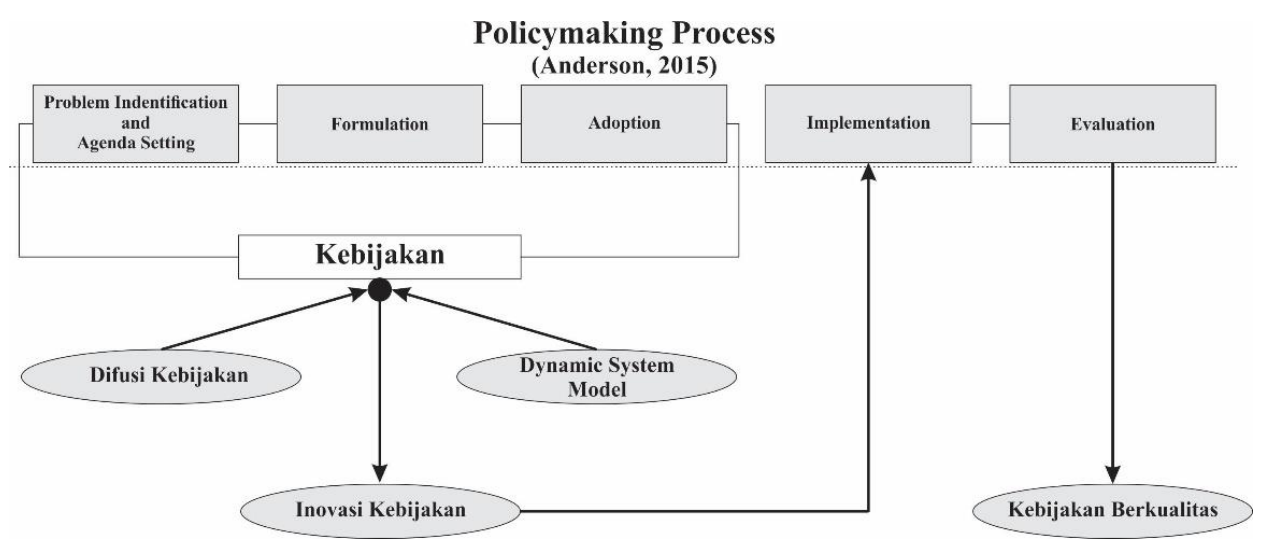

Gambar 2.

Redesain Model Proses Kebijakan (simulation testing)

-nunjukkan adanya interaksi kausalitas antara beberapa cara atau model yang memengaruhi proses kebijakan seperti difusi kebijakan dan dynamic system model.

\section{Difusi Kebijakan}

Aktivitas pembuatan kebijakan dapat terjadi melalui berbagai pilihan yang sering dikaitkan dengan difusi. Difusi kebijakan dipengaruhi oleh pilihan 


\section{Jurnal Ilmu Pemerintahan: Kajian Ilmu Pemerintahan dan Politik Daerah, \\ Vol. 3 (1), April 2018 - 26 \\ Lesmana Rian Andhika}

kebijakan tertentu dalam waktu dan tempat yang berbeda. Makna yang tersirat, mengindikasikan bentuk difusi kebijakan merupakan pilihan kebijakan yang diambil (diadopsi) terhadap kebijakan yang sukses di tempat yang berlainan untuk dianalisis dan dipelajari oleh orang, institusi di tempat yang berbeda. Dengan desentralisasi, pemerintah daerah lebih terbuka untuk merangsang inovasi dan difusi kebijakan dalam praktek yang nyata.

Walker (1969) menyebut diffusion theory suggests that policy-making activity at the state level may occur either through internal processes or by building on what has occurred in other states. Boushey (2010) memberikan argumentasi, the process of public policy diffusion can be gained by integrating research on innovation diffusion with studies of agenda setting in political decision making. Pandangan ini merujuk kepada proses politik untuk pengambilan keputusan sebuah kebijakan. Konsepsi difusi kebijakan juga dapat dijumpai dari pandangan Braun dan Gilardi (2006); Maggetti dan Gilardi (2015); Gilardi (2016) memberikan pengertian difusi kebijakan adalah process whereby policy choices in one unit are influenced by policy choices in other units. Disisi lain difusi kebijakan dianggap sebagai concerns the spread of policies from government to government (Volden, Ting, \& Carpenter, 2008; Shipan \& Volden, 2008; Nicholson-Crotty \& Carley, 2016).

Sebelum kebijakan dirumuskan perlu dipertimbangkan melakukan studi kelayakan terhadap sebuah kebijakan yang akan diputuskan, pernyataan ini juga direkomendasikan oleh beberapa praktisi agar kebijakan yang dihasilkan berkualitas (Shipan \& Volden, 2008, 2012; Meseguer \& Gilardi, 2009; Maggetti \& Gilardi, 2015; Gilardi, 2016). Studi kelayakan sering dianggap hanya melihat dan menyerap, namun difusi kebijakan bukanlah seperti itu. Difusi kebijakan tidak bisa dilakukan hanya untuk melihat dan menyerap kebijakan yang sukses pada daerah tertentu, tapi ada kausalitas yang harus dipenuhi. Kausalitas itu dapat memengaruhi difusi kebijakan seperti, budaya daerah yang sama, kedekatan goegrafis memberikan tingkat keberhasil-an difusi semakin tinggi. Kualitas sumberdaya manusia legislatif dan eksekutif akan berdampak kepada analisis adopsi kebijakan, situasi politik yang kondusif menjadi awal kerjasama antara legislatif dan eksekutif untuk perencanaan difusi kebijakan. Disisi lain ada efek difusi yang berbeda untuk adopsi kebijakan, bahwa proses amandemen kebijakan, adopsi kebijkan memerlukan legislatif yang lebih profesional, dan pengetahuan yang cukup untuk mengubah dan memengaruhi proses adopsi (Baybeck, Berry, \& Siegel, 2011; Fay \& Wenger, 2015).

\section{Dynamic System Model}

Model ini kurang terungkap melalui studi dalam negeri yang dapat ditelusuri dari berbagai literatur ilmiah yang dipublikasikan, namun model ini telah digunakan untuk mendapatkan berbagai opsi kebijakan pada negaranegara maju, sebagian negara berkembang, dan sering digunakan untuk proses kebijakan diberbagai sektor dengan mem-pertimbangkan kausalitas diantara beberapa 


\section{Jurnal Ilmu Pemerintahan: Kajian Ilmu Pemerintahan dan Politik Daerah, \\ Vol. 3 (1), April 2018 - 27 \\ Lesmana Rian Andhika}

kemungkinan yang mem-pengaruhi. Model ini juga bukanlah sesuatu yang baru ratusan jurnal ilmiah, dan puluhan buku ilmiah dari luar negeri mengungkapkan pengunaan model ini dalam proses awal kebijakan.

Istilah dinamis mengacu pada fenomena yang menghasilkan pola perubahan, karakteristik, pada satu waktu saling terkait dengan yang ada di waktu lain. Istilah ini hampir sama dengan time-evolution atau pattern of change. Sistem dinamis adalah sebuah model dalam ilmu matematika. Biasanya digunakan dalam menganalisis konsep engineering disciplines, seperti electrical, mechanical, civil, dan chemical engineering dan berkembang untuk menganalisis berbagai model pendekatan dalam studi ekonomi, demografi, dan sosial. Namun banyak sistem dinamis dapat dipahami dan dianalisis secara intuitif, tanpa menggunakan matematika dan tanpa pengembangan teori dinamika umum (Luenberger, 1979; Rowell \& Wormley, 1997). Hampir semua fenomena yang diamati dalam kehidupan kita seharihari atau dalam penelitian ilmiah memiliki aspek dinamis yang penting. Contoh studi kebijakan, merupakan seperangkat aturan yang ada dalam pemerintah, sektor bisnis, maupun organisasi non pemerintah. Kebijakan tidak hanya bercerita tentang cara perumusan, pelaksanaan dan evaluasi, yang terpenting kebijakan tersebut akan menimbulkan berbagai implikasi, kausalitas, memberikan perubahan pada stuktur organisasi, ekonomi, pengembangan sosial budaya dan berbagai area. Implikasi ini yang seharusnya dapat dipahami sebagai situasi dinamis yang menunjukkan potensi pengembangan perencanaan kebijakan tingkat lanjut untuk mewakili dan menganalisis dinamika perubahan yang menyebabkan kebijakan baik atau tidak.

Beberapa pengunaan model dinamis dalam kebijakan dapat ditelusuri dari beberapa studi yang pernah dilakukan. Kiani dan Pourfakhraei (2010) mengungkapkan, diantara tiga strategi yang dinamis antara conter effect, umpan balik, dan sistem penawaran dan pembelian akan mempertimbangkan sektor ekonomi dan sektor lain dari berbagai kemungkinan pengaruh terhadap kebijakan energi (kasus negara Iran). Sayyadi dan Awasthi (2016) mengusulkan model dynamic system model dalam mengevaluasi kebijakan transportasi untuk perencanaan sistem transportasi berkelanjutan dangan memperhatikan kausalitas antara sistem transportasi, hubungan yang saling memengaruhi, dan evolusi perilaku masyarakat yang terus berubah (kasus yang umum terjadi di setiap negara).

Dynamic System Model dapat membangun hubungan kausalitas yang diperlukan dalam proses awal kebijakan, dan juga mencakup semua entitas hubungan utama efek kausalitas. Model ini juga sebagai alat mendukung setiap keputusan praktis yang memungkinkan untuk menguji efektivitas berbagai skenario kebijakan (Rashedi \& Hegazy, 2015; Bérard, Cloutier, \& Cassivi, 2016). Duggan (2016) menyebut, the model building process focuses on a part of reality that needs to be understood and managed, and creates an external and explicit representation, in the form of a 


\section{Jurnal Ilmu Pemerintahan: Kajian Ilmu Pemerintahan dan Politik Daerah, Vol. 3 (1), April 2018 - 28 \\ Lesmana Rian Andhika}

model, of this reality. Disisi lain penggunaan dynamic system model sebagai petunjuk untuk pengembangan kebijakan (Coyle, 1996). Petunjuk itu diterjemahkan dalam berbagai aktivitas memahami komponen kebijakan itu seperti struktur kebijakan. Struktur kebijakan merujuk kepada sesuatu yang disusun dengan pola tertentu. Struktur yang tekandung dalam setiap kebijakan memiliki aspek filosofis, nilai, norma, pengaruh (lihat lebih lanjut Kay, 2006).

Oleh sebab itu penggunaan dynamic system model akan lebih mungkin terjadi untuk menghasilkan kebijakan yang berkualitas, dengan mempertimbangkan efek dari kebijakan itu sendiri terhadap berbagai aktivitas disektor lain. Pada tahap perumusan kebijakan model ini akan mengidentifikasi kausalitas dari berbagai sektor/konsep, teori/disiplin ilmu yang mungkin akan memengaruhi secara signifikan.

\section{SIMPULAN DAN SARAN}

\section{Simpulan}

Banyak penyebab mengapa publik (warga negara) cenderung percaya ataupun tidak percaya terhadap pemerintah. Kasus-kasus penyimpangan yang terjadi memberikan gambaran betapa buruknya integritas para penyelenggara negara, tata kelola dan pelayanan publik yang buruk. Oleh sebab itu berbagai upaya dilakukan pemerintah untuk lebih meningkatkan kepercayaan publik dengan berbagai inisiasi seperti reformasi birokrasi, pembentukan lembaga anti rasuah, dan inisiasi lainnnya. Ketika masyarakat melakukan respon terhadap pemerintah meng- indikasikan tingkat ketidakpercayaan publik mulai meningkat.

Salah satu penyebab yang dapat meningkatkan atau menurunkan kepercayaan publik terhadap pemerintah berupa produk kebijakan yang dihasilkan cenderung bertentangan dengan aturan yang lebih tinggi dan juga kebijakan itu sering tidak berkualitas terutama kebijak-an yang dihasilkan oleh Pemerintah Daerah. Proses kebijakan tingkat lokal mengisyaratkan perubahan dalam berbagai bentuk penawaran model yang dianggap lebih baik. Berbagai model tersebut bukanlah sesuatu yang absolut tetapi bersifat dimanis yang dapat berubah sesuai dengan tujuan, kondisi dan kemampuan antara legislatif dan eksekutif. Artikel penelitian ini menawar-kan pengaruh terhadap proses awal kebijakan untuk mendapatkan kebijakan yang berkualitas diantara difusi kebijakan dan dynamic system model dalam mode simulasi percobaan. Ketika kebijakan baru akan diumumkan maka kepercayaan dan ketidakpercayaan publik memberi-kan respon terhadap kebijakan itu sendiri. Argumentasi ini juga didukung oleh berbagai argumentasi dari beberapa praktisi kebijakan publik.

Ketika publik telah percaya terhadap pemerintah maka yang terjadi adalah negara lebih leluasa menjalankan setiap kegiatan negara dalam bentuk program-program pemerintah, investasi akan tumbuh subur yang akan meningkatkan prekonomian masyarakat, dan dengan mudah negara dapat mensejahterakan warga negaranya. Stabilitas politik akan menghasilkan berbagai implikasi kebijakan yang berpihak kepada 


\section{Jurnal Ilmu Pemerintahan: Kajian Ilmu Pemerintahan dan Politik Daerah, \\ Vol. 3 (1), April 2018 - 29 \\ Lesmana Rian Andhika}

kepentingan umum yang juga akan menjaga stabilitas negara secara umum.

\section{Saran}

Saran yang dapat diusulkan sebagai inti sari untuk memberikan kontribusi pemikiran lebih lanjut adalah pertama area pemerintah, melakukan berbagai bentuk inovasi kebijakan berkualitas dengan cara melakukan simulation testing model dalam proses awal kebijakan. Kedua area sistem politik, kondisi politik yang stabil akan cenderung menghasilkan berbagai produk kebijakan yang berkualitas, berimplikasi terhadap aktivitas pemerintah untuk menjalankan setiap program. Ketiga, kepercayaan publik yang meningkat akan memudahkan pemerintah untuk perencanaan dan pembangunan nasional berkelanjutan, ketidakpercayaan publik adalah hal yang biasa terjadi sebagai respon terhadap berbagai aktivitas pemerintah. Ketidakpercayaan ini menjadi peringatan kepada pemerintah untuk lebih berupaya mencari cara meningkatkan kepercayaan publik melalui kebijakan pro rakyat. Akhirnya saran untuk peneliti lain, agar dapat menggungkapkan model yang berbeda dalam mendesain ulang proses awal kebijakan tingkat lokal, agar diketahui ragam bentuk model yang dapat dijadikan pilihan dan diadopsi untuk memroduksi kebijakan yang berkualitas dari sudut pandang, dan mungkin saja dari disiplin ilmu yang berbeda.

\section{DAFTAR PUSTAKA}

Aghion, P., Algan, Y., Cahuc, P., \& Shleifer, A. (2010). Regulation and Distrust. The Quarterly Journal of
Economics, 125(3), 1015-1049. doi:10.3386/w14648

Anderson, J. E. (2015). Public Policymaking: An Introduction (8th ed.). Stamford, CT: Cengage Learning.

Attard, J., Orlandi, F., Scerri, S., \& Auer, S. (2015). A Systematic Review of Open Government Data Initiatives. Government Information Quarterly, 32(4), 399418. doi:10.1016/j.giq.2015.07.006

Autant-Bernard, C., Fadairo, M., \& Massard, N. (2013). Knowledge Diffusion and Innovation Policies Within The European Regions: Challenges Based on Recent Emperical Evidence. Research Policy, 42(1), 196-210. doi:10.1016/j.respol.2012.07.00 9

Baybeck, B., Berry, W. D., \& Siegel, D. A. (2011). A Strategic Theory of Policy Diffusion via Intergovernmental Competition. The Journal of Politics, 73(1), 232247. doi:10.1017/S00223816100009 88

Bender, K., Keller, S., \& Willing, H. (2014). The Role of International Policy Transfer and Diffusion for Policy Change in Social Protection-A Review of the State of the Art. International Policy Learning and Policy Change: Scientific Inputs for the Dialogue on Social Protection with Global Partners (pp. 1-18). Bonn: Deutsche Gesellschaft für Internationale Zusammenarbeit (GIZ) GmbH and Bonn-Rhein-Sieg University of Applied Sciences / International Centre for Sustainable Development (IZNE). Bérard, C., Cloutier, L. M., \& Cassivi, L. (2016). The Effects of Using System Dynamics-Based Decision Support Models: Testing Policy- 
Jurnal Ilmu Pemerintahan: Kajian Ilmu Pemerintahan dan Politik Daerah,

Vol. 3 (1), April 2018 - 30

Lesmana Rian Andhika

Makers' Boundaries in a Complex Situation. Journal of Decision Systems, 26(1), 45-63. doi:10.1080/12460125.2016.120 4212

Bianco, W. T. (1994). Trust: Representatives and Constituents. Michigan: The University of Michigan Press.

Blind, P. K. (2006). Building Trust in Government int the Twenty-Firts Century: Review of Literature and Emerging Issues. 7th Global Forum on Reinventing Government Building Trust in Government (pp. 1-31). Vienna: United Nations.

Boushey, G. (2010). Policy Diffusion Dynamics in America. New York, NY: Cambridge University Press.

Bovens, M., \& Hart, P. (2016). Revisiting the Study of Policy Failures. Journal of European Public Policy, 23(5), 653-666. doi:10.1080/13501763.2015.112 7273

Bozeman, B. (2000). Bureaucracy and Red Tape. New Jersey: Prentice Hall.

Braun, D., \& Gilardi, F. (2006). Taking 'Galton's Problem Seriously: Towards Theory of Policy Diffusion. Journal of Theoretical Politics, 18(3), 298-322. doi:10.1177/095162980606435 1

Caiden, G. E. (1991). What Really Is Public Maladministration? Public Administration Review, 51(6), 486-493.

Caiden, G. E. (2009). Administrative Reform. Chicago: Aldine Transaction.

Chanley, V. A., Rudolph, T. J., \& Rahn, W. H. (2000). The Origins and Consequences of Public Trust in Government. Public Opinion Quarterly, 64(3), 239-256. doi:10.1086/317987
Chen, W. Y., \& Hua, J. (2015). Citizens' Distrust of Government and Their Protest Responses in a Contingent Valuation Study of Urban Heritage Trees in Guangzhou, China. Journal of Environmental Management, 155, 40-48. doi:10.1016/j.jenvman.2015.03.0 02

Cheung, A. B. (2013). Public Governance Reform in Hong Kong: Rebuilding Trust and Governability. International Journal of Public Sector Management, 26(5), 421436. doi:10.1108/IJPSM-052013-0070

Cierco, T. (2013). Public administration reform in Macedonia. Communist and Post-Communist Studies, 46(4), 481-491. doi:10.1016/j.postcomstud.2013. 08.002

Coyle, R. (1996). System Dynamics Modelling: A Practical Approach. New York: SpringerScience+Business Media.

Duggan, J. (2016). System Dynamics Modeling with $R$. Switzerland : Springer International Publishing.

Fähnrich, B. (2013). Integrating Concepts of International Governmental Communication A Framework for Further Research. Studies in Communication Sciences, 13(1), 15-23.

doi:10.1016/j.scoms.2013.01.001

Fay, D. L., \& Wenger, J. B. (2015). The Political Structure of Policy Diffusion. The Policy Studies Journal, 44(3), 349-365. doi:10.1111/psj.12122

Frederickson, et al. (2012). The Public Administration Theory Primer. Boulder: Westview Press.

Fukuyama, F. (1995). Trust: The Social Virtues and the Creation of Prosperity. New York, NY: Free Press. 
Jurnal Ilmu Pemerintahan: Kajian Ilmu Pemerintahan dan Politik Daerah,

Vol. 3 (1), April 2018 - 31

Lesmana Rian Andhika

Fuoli, M., \& Paradis, C. (2014). A Model of Trust-Repair Discourse. Journal of Pragmatics, 74, 52-69. doi:10.1016/j.pragma.2014.09.0 01

Gerston, L. N. (2010). Public Policy Making Process and Principles (3rd ed.). New York: M.E. Sharpe.

Gilardi, F. (2016). Four Ways We Can Improve Policy Diffusion Research. State Politics \& Policy Quarterly, 16(1), 8-21. doi:10.1177/153244001560876 1

Grindle, M. S. (1980). Politics and Policy Implementation in the Third World. New Jersey: Princeton University Press.

Grindle, M. S., \& Thomas, J. W. (1989). Policy Makers, Policy Choices, and Policy Outcomes: The Political Economy of Reform in Developing Countries. Policy Science, 22(3-4), 213-248.

doi:10.1007/BF00136320

Grimmelikhuijsen, S., \& Knies, E. (2015). Validating a Scale for Citizen Trust in Government Organizations. International Review of Administrative Science, 0(0), 1-19. doi:10.1177/002085231558595 0

Hacek, M., Kukovic, S., \& Brezovsek, M. (2013). Problems of Corruption and Distrust in Political and Administrative Institutions in Slovenia. Communist and PostCommunist Studies, 46(2), 255261.

doi:10.1016/j.postcomstud.2013. 03.004

Hardin, R. (2002). Trust and Trustworthiness. New York: Russell Sage Foundation.

Hill, M. (2005). The Public Policy Process (4th ed.). Essex: Pearson Education.

Holzhacker, R. L., Wittek, R., \& Woltjer, J. (2016). Decentralization and
Governance in Indonesia. Switzerland: Springer International Publishing AG.

Jaccard, J., \& Jacoby, J. (2010). Theory Construction and Model-Building Skills: A Practical Guide for Social Scientists. New York, NY: Guilford Press.

Kay, A. (2006). The Dynamics of Public Policy: Theory and Evidence. Cheltenham: Edward Elgar.

Kementrian Dalam Negeri. (2016, Juni 21). Unggah 3.143 Perda, Mendagri Berterimakasih ke Semua Pihak. Retrieved from Kementrian Dalam Negeri : http://www.kemendagri.go.id/n ews/2016/06/21/unggah-3143perda-mendagri-berterimakasihke-semua-pihak

Kiani, B., \& Pourfakhraei, M. A. (2010). A System Dynamic Model for Production and Consumption Policy in Iran Oil and Gas Sector. Energy Policy, 38(12), 7764-7774. doi:10.1016/j.enpol.2010.08.036

Kim, S. (2010). Public Trust in Government in Japan and South Korea: Does the Rise of Critical Citizens Matter? Public Administration Review, 70(5), 801-810. doi:10.1111/j.15406210.2010.02207.x

Kim, S., \& Han, C. (2014). Administrative Reform in South Korea: New Public Management and the Bureaucracy. International Review of Administrative Science, $O(0)$, 1-19. doi:10.1177/002085231455803 4

Lenard, P. T. (2015). The Political Philosophy of Trust and Distrust in Democracies and Beyond. The Monist, 98(4), 353-359. doi:10.1093/monist/onv017

Lindstedt, C., \& Naurin, D. (2010). Transparency is not Enough: Making Transparency Effective in 
Jurnal Ilmu Pemerintahan: Kajian Ilmu Pemerintahan dan Politik Daerah,

Vol. 3 (1), April 2018 - 32

Lesmana Rian Andhika

Reducing Corruption.

International Political Science

Review, 31(3), 301-322.

doi:10.1177/019251211037760

2

Lindvall, J. (2011). The Political Foundations of Trust and Distrust: Reforms and Protests in France. West European Politics, 34(2), 296-316. doi:10.1080/01402382.2011.546 575

Luenberger, D. G. (1979). Introduction to Dynamic System: Theory, Models and Applications. New York: John Wiley \& Sons.

Maggetti, M., \& Gilardi, F. (2015). Problems (and Solutions) in the Measurement of Policy Diffusion Mechanisms. Journal of Public Policy, $\quad 00(0), \quad 1-21$. doi:10.1017/S0143814X140003 $5 \mathrm{X}$

Marková, I., \& Gillespie, A. (2012). Trust and Conflict: Representation, Culture and Dialogue. East Sussex: Routledge.

Meseguer, C., \& Gilardi, F. (2009). What is New in the Study of Policy Diffusion? Review of International Political Economy, 16(3), 527-543. doi:10.1080/096922908024092 36

Michels, A., \& Graaf, L. D. (2010). Examining Citizen Participation: Local Participatory Policy Making and Democracy. Local Government Studies, 36(4), 477491.

doi:10.1080/03003930.2010.494 101

Nicholson-Crotty, S., \& Carley, S. (2016). Effectiveness, Implementation, and Policy Diffusion: Or "Can We Make That Work for Us?". State Politics \& Policy Quarterly, 16(1), 78-97. doi:10.1177/153244001558876 4
OECD. (2016, 12 12). Trust in Government. Retrieved from OECD:

http://www.oecd.org/gov/trustin-government.htm

Ombudsman Republik Indonesia. (2016). Laporan Tahunan 2015. Jakarta: Ombudsman Republik Indonesia.

Oomsels, et al. (2016). Functions and Dysfunctions of Interorganizational Trust and Distrust in the Public Sector. Administration \& Society, 1-29. doi:10.1177/009539971666797 3

O'Toole, L. J. (1986). Policy Recommendations for MultiActor Implementation: An Assessment of the Field. Journal of Public Policy, 6(2), 181-210. doi:10.1017/S0143814X000064 86

Peisakhin, L. (2012). Transparency and Corruption: Evidence From India. The Journal of Law \& Economics, 55(1), 129-149. doi:10.1086/663727

Purwanto, E. A., \& Sulistyastuti, D. R. (2015). Implementasi Kebijakan Publik; Konsep dan Aplikasinya di Indonesia (2nd ed.). Yogyakarta: Gava Media.

Rashedi, R., \& Hegazy, T. (2015). Strategic Policy Analysis for Infrastructure Rehabilitation Using System Dynamics. Structure and Infrastructure Engineering, 12(6), 667-681. doi:10.1080/15732479.2015.103 8723

Rindermann, H., Kodila-Tedika, O., \& Christainsen, G. (2015). Cognitive Capital, Good Governance, and the Wealth of Nations. Intelligence, 51 , 98-108. doi:10.1016/j.intell.2015.06.002

Rosanvallon, P. (2008). Counter Democracy: Politics in an Age 
Jurnal Ilmu Pemerintahan: Kajian Ilmu Pemerintahan dan Politik Daerah,

Vol. 3 (1), April 2018 - 33

Lesmana Rian Andhika

Distrust. New York: Cambridge University Press.

Rosenbloom, D. H., O'Leary, R., \& Chanin, J. (2010). Public Administration and Law (3rd ed.). Boca Raton, FL: CRC Press.

Rowell, D., \& Wormley, D. N. (1997). System Dynamics: An Introdustion. Upper Saddle River, NJ: PrenticeHall.

Salminen, A., \& Ikola-Norrbacka, R. (2010). Trust, Good Governance and Unethical Actions in Finnish Public Administration. International Journal of Public Sector Management, 23(7), 647668.

doi:10.1108/095135510110789 05

Sayyadi, R., \& Awasthi, A. (2016). A System Dynamics Based

Simulation Model to Evaluate Regulatory Policies for Sustainable Transportation Planning. International Journal of Modelling and Simulation, 37(1), 25-35.

doi:10.1080/02286203.2016.121 9806

Saz-Carranza, A., \& Serra, A. (2009). Institutional Sources of Distrust in Government Contracting. Public Management Review, 11(3), 263-279.

doi:10.1080/147190309027982 06

Shabbir, C. C., \& Rondinelli, D. A. (2007). Decentralization Governance Emerging Concept and Practice. Washington DC: Brooking Institute Press.

Shipan, C. R., \& Volden, C. (2008). The Mechanisms of Policy Diffusion. American Journal of Political Science, 52(4), 840-857. Retrieved from

http://www.jstor.org/stable/251 93853
Shipan, C. R., \& Volden, C. (2012). Policy Diffusion: Seven Lessons for Scholars and Practitioners. Public Administration Review, 72(6), 788-796. doi:10.111/j.15406210.2012.02610.x.

Smith, K. B., \& Larimer, C. W. (2009). The Public Policy Theory Primer. Boulder, CO: Westview Press.

Stewart, J. (2009). Public Policy Values. Hampshire: Palgrave Macmillan.

Tambulasi, R. I., \& Kayuni, H. M. (2007). Decentralization Opening a New Window for Corruption: An Accountability Assessment of Malawi's Four Years of Democratic Local Governance. Journal of Asian and African Studies, 42(2), 163-183. doi:10.1177/002190960707486 6

Tang, M., \& Huhe, N. (2014). The Variant Effect of Decentralization on Trust in National and Local Governments in Asia. Political Studies, 64(1), 216-234. doi:10.1111/1467-9248.12177

Tholen, B. (2015). Citizen Participation and Bureaucratization: the Participatory Turn Seen Through a Weberian Lens. International Review of Administrative Sciences, $O(0)$, 1-19. doi:10.1177/002085231454815 2

Tolbert, P. S. (2010, May 04). Robert Michels and the Iron Law of Oligarchy. Retrieved from Cornell University, ILR School: http://digitalcommons.ilr.cornell .edu/articles/397/

Trägårdh, L. (2013). Commentary: The Politics of Distrust. Journal of Civil Society, 9(1), 100-104. doi:10.1080/17448689.2013.784 503

Vincent, A. (2010). Modern Political Ideologies (3rd ed.). West Sussex: Wiley-Blackwell. 
Jurnal Ilmu Pemerintahan: Kajian Ilmu Pemerintahan dan Politik Daerah,

Vol. 3 (1), April 2018 - 34

Lesmana Rian Andhika

Volden, C., Ting, M. M., \& Carpenter, D. P. (2008). A Formal Model of Learning and Policy Diffusion. The American Political Science Review, 102(3), 319-332. Retrieved from http://www.jstor.org/stable/276 44523

Walker, J. L. (1969). The Diffusion of Innovations Among The American States. American Political Science Review, 63(3), 880-899. Retrieved from

http://www.jstor.org/stable/195 4434

Walle, S. V., \& Bouckaert, G. (2003). Public Service Performance and Trust in Government: The Problem of Causality. International Journal of Public Administration, 26(8-9), 891-913. doi:10.1081/PAD-120019352

Walle, S. V., \& Six, F. (2014). Trust and Distrust as Distinct Concepts: Why Studying Distrust in Institutions is Important. Journal of Comparative Policy Analysis: Research and Practice, 16(2), 158174.

doi: 10.1080/13876988.2013.785146

Walle, S. V., Roosbroek, S. V., \& Bouckaert, G. (2008). Trust in the Public Sector: Is There Any Evidence for a Long-Term Decline? International Review of Administrative Science, 74(1), 4764.

doi:10.1177/002085230708573 3

Wilkes, R. (2015). We Trust in Government, Just Not in Yours: Race, Partisanship, and Political Trust, 1958-2012. Social Science Research, 49(1), 356-371. doi:10.1016/j.ssresearch.2014.0 8.008

\section{PROFIL SINGKAT}

Lesmana Rian Andhika, lahir di Aceh Tenggara, 23 Agustus 1981. Menamatkan pendidikan S1 Ilmu Ekonomi Manajemen di STIE Harapan Medan pada tahun 2005 dan menyelesaikan pendidikan Magister Administrasi Publik di Universitas Pasundan (UNPAS) Bandung pada tahun 2012. Saat ini aktif menjalani tugas belajar pada FISIP Program Doktor Ilmu Administrasi Konsentrasi Administrasi Publik Universitas Padjadjaran (UNPAD) Bandung dari tahun 2015-sekarang. 